My main concern is that the human reality represented in the bald figures sometimes escape our notice in such debates. That it is better to be dead than handicapped is not obvious. It is however, a necessary assumption if one is to justify not treating infants because some of the survivor will have varying degrees of handicap. If this assumption is to underlie public policy-for example, in a weight or gestation limit for the initiation of neonatal intensive care-many infant will die who would have survived intact and many will die who would have survived with varying degrees of handicap. Using the figures of Professor V Y H Yu and others (8 November, p 1200), to avoid each additional handicapped survivor in the 23-25 week group we would allow one infant who would otherwise have survived without handicap to die (assuming a $42 \%$ handicap rate in survivors and $100 \%$ mortality in those not treated). As the accurate assessment of gestation in such infants is difficult, many errors will be made, especially as such decisions are often made by junior obstetric and paediatric staff. There are always those infants who do not oblige by dying quickly and who are then either subjected to a prolonged period of distress until death or changed to aggressive management after a period of suboptimal care.

The definition of handicap used by Professor Yu and his colleagues is conventional and covers a wide range of disability, from those with mild cerebral palsy attending normal school to those with profound mental and physical handicap and little prospect of meaningful human contact. At which point on this continuum is one better of dead? As medical practitioners we are morally obliged to act in the best interest of our patients, in this case the child. We must surely then attempt to make such a judgment in each individual case and use this in deciding when we have reached the point at which we are "striving officiously...."

It is not possible to predict outcome on day 1 in the individual infant. The picture becomes clearer in the next day or so, as shown by Professor Yu and colleagues. It is a more difficult decision to withdraw established treatment, but this policy has many advantages. One has the advantage of a far better relationship with parents and a clearer understanding of the outlook for the infant. The practice of not initiating treatment results in these decisions being made at delivery by junior staff, at a time when the family have had no rea opportunity to grasp the issues, as is surely their right. Senior staff with an established relationship can provide far better support for the family, both at the time and after the death of the infant, should this be the decision.

There is no reason to believe that the prognosis for these infants will not further improve. It will not improve if we do not treat them. Medical resources are not infinite, but it is clear that in Britain we are entitled to expect more than is currently provided. Let us at least consider the human impact of our decisions.

ANDREW WATKINS

Regional Neonatal Intensive Care Unit,

Liverpool Maternity Hospital,

Liverpool L7 7BN

\section{A new health region for London?}

SIR,-Dr A K Thould's letter on the possibility of a new health region for London (17 January, p 181) offers a tantalising solution to the constan problems which beset the outer parts of the Thames regions. There can be no doubt that the division of the city and home counties into the fou Thames regions has been a disaster for both parties.

The peripheral parts of the regions continue to be drained of resources because of the way that RAWP has been applied to the London districts, while these same districts maintain a centripetal myopia. The boundary between South East and South West Thames regions provides an entirely artificial barrier between parts of Sussex. The logical provision of services on either side of this boundary is constantly hindered.

Dr Thould's suggestion should be taken most seriously. The South East Thames Regional Health Authority has already signalled the logic of a south coast regional health authority by moving its offices from Croydon to Bexhill on Sea. This would provide an ideal focus for a region covering west and east Sussex, Kent, and parts of Surrey. Serious consideration should be given to this proposal.

Department of Pathology,
Royal Sussex County Hospital,

Brighton BN2 5BF

Nigel KIRKHAM

\section{How much should private medicine cost?}

SIR,-At frequent intervals we hear from the medical provident societies that subscriptions are to be increased. This is usually accompanied by publicity in the medical press asking that consultants do not increase their fees to patients. Perhaps before losing too much sleep over this matter your readers would be interested to hear my own recent experience.

I had to undergo an arthroscopic operation. The inpatient stay for this was under 24 hours but did not include overnight accommodation. The time spent in the operating theatre was about one hour. The fee, excluding any charges from the medical staff, was $£ 2050$. When submitting the account to my insurers I did write to say that I wondered if there was a mistake but received only an acknowledgement to say that the sum had been paid. Is it the provident associations or ourselves who have a wrong sense of priorities?

Beckenham, Kent BR3 2RP

M G WRIGHT

\section{Death in the clouds}

SIR,-Some reply is required to $\mathrm{Mr}$ Richard Wakeford's article (20-27 December, $p$ 1642) and to the letter by Drs P J C Chapman and D A Chamberlain (17 January, p 181).

Firstly, the cabin crew in British Airways are highly trained in first aid and resuscitation and do not rely "on the chance presence of a doctor to deal with the more serious emergencies." Indeed, the presence of such a doctor, if he is skilled in such matters, is a bonus and we were very grateful for the help given by $\mathrm{Mr}$ Wakeford and an American doctor on this sad occasion, and both have been thanked for their efforts.

However, I must say that the cabin crew concerned performed well beyond the normal call of duty. Indeed, the unfortunate passenger was first thought to have suffered from some form of food poisoning-although he had not eaten on board. Additionally, he was very dehydrated and it was thought he might be suffering from a diabetic condition. Because he lapsed into unconsciousness the captain came back to assess the situation and decide whether to divert to Gander or return to Heathrow. Shortly afterwards the patient collapsed. The two cabin crew members were able to give him cardiopulmonary resuscitation and some recovery was noted. Sadly, he later collapsed and died.

We have looked carefully at the use of in fligh defibrillators, as advocated by Drs Chapman and
Chamberlain. We believe that to be competent in $\square$ the use of these you have to be in constant practice, dealing with real emergency cases, and that an $\overline{\mathcal{D}}$ itinerant doctor would certainly not be competent $\Omega$ to deal with such equipment at first sight on an aircraft.

At present we are looking at three ways of $\overline{\bar{J}}$ improving medical training for cabin crew and the facilities aboard aircraft. Firstly, we are looking $\mathbb{\Phi}$ at extended medical training for selected cabin crew members; secondly, we intend to fit cardiac $?$ monitors which can be telemetered via an in flight $\overrightarrow{\vec{F}}$ telephone system and satellite to our consultant $\stackrel{\oplus}{\sim}$ cardiologist; and, thirdly, we are revising first aid kits in keeping with these changes.

FRANK S PRESTON $\frac{\pi}{\stackrel{0}{\circ}}$

British Airways Medical Service,

London (Heathrow) Airport,

Middlesex TW6 2JA

Vaccine related poliomyelitis in non-immunised relatives and household contacts

SIR,-Dr D E Bateman and colleagues suggest that "non-immunised parents and household con- of tacts of children receiving primary immunisation $\overbrace{\infty}$ should be immunised against poliomyelitis at the $\dot{\omega}$ same time as their children" (17 January, p 170). They present a logical case for a policy which is similar to that advocated by the DHSS. ${ }^{1}$ However, $ᄋ$ is the policy practical and is it desirable?

Polio vaccination began in 1956 and from its outset had a high rate of uptake. We can expect $\mathbb{D}$ $80-90 \%$ of parents to have completed a primary course. Experience in clinics is that most mothers assume they have been immunised but few are $₹$ certain and hardly any can produce documenta- $\vec{\bullet}$ tion. How many doctors can lay their hands on their own immunisation records? We are at least $a$. decade away from the time when children who now have computerised immunisation records will have children themselves. So, apart from a few families where grandmother is known to have vetoed all immunisation, it is almost impossible to identify $\mathbb{D}$ the $10 \%$ of parents who are unprotected. This is one reason why most child health clinics ignore the DHSS recommendations and would find the policy unworkable.

To ensure universal protection would require offering polio drops to every parent and household contact, most of whom would already be immune. Aside from considerations of finance and admini- . stration such a blanket policy would not be without morbidity. Vaccine induced polio is a rare but inevitable consequence of mass immunisation, and $\delta$ immunising those not at risk should not be done lightly.

Department of Child Health,

ANGUS NiCOLL N

University Hospital,

1 Department of Health and Social Security. Immunisation against infectious disease. London: DHSS, 1984:27.

\section{Correction}

Association between liberalisation of Scotland's liquor licensing laws and admissions for self poisoning

An error occurred in this letter by Drs S P Lockhart and $J \mathrm{H}$ Baron (10 January, p 116). The $\chi^{2}$ value should have read $4 \cdot 3$, not 43 ; the associated $p$ value and the conclusion remain correct. 